Die nationalpolitische Bedeutung der Germanistik im 19. Jahrhundert

\title{
Podiumsgespräch mit Alan Kirkness, Ruth Römer und Hartmut Schmidt
}

Moderation: Helmut Henne

\section{Vorbemerkung}

Wenn das Podiumsgespräch und die sich daran anschließende Diskussion zu einem (guten) Ende geführt sind, endet zugleich die Aufgabe desjenigen, der das Gespräch vorbereitet und geleitet hat. Ich sah meine Funktion vor allem darin, die Beteiligten „zu Wort" kommen zu lassen und zuzuhören. Diese Rolle möchte ich durchhalten. Soviel aber darf ich doch sagen: Beeindruckt hat mich der Ernst, mit dem die Argumente vorgetragen und zur Kenntnis genommen wurden. Dabei wurde wiederum deutlich, daß zur Germanistik notwendig die Geschichte ihres Faches gehört; daß diese Geschichte von jeder Generation nicht neu geschrieben, wohl aber neu akzentuiert und bewertet werden muß. Nur so sind die Fragen, die hier anschließend gestellt und diskutiert werden (nunmehr schriftlich erweitert), zureichend zu beantworten. Die Grimms und ihre Vorläufer und Nachfolger haben fortwährend Geburtstag. H.H. 